\title{
Obstructed Diaphragmatic Hernia in Children: Report of Two Cases
}

\author{
Samiul Hasan, Saifullah Shafique, Gajendra Nath Mahato and Rashedul Alam \\ Dhaka Shishu, Bangladesh
}

*Corresponding author: Samiul Hasan, Registrar (Pediatric surgery), Dhaka Shishu (Children) Hospital, Shere Bangla Nagar, Dhaka, Bangladesh

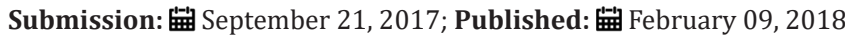

\begin{abstract}
Congenital diaphragmatic hernia usually present in early neonatal period. Few cases present later in child hood with respiratory symptoms but presenting with intestinal obstruction is very rare. We describe two patients of congenital diaphragmatic hernia presenting with intestinal obstruction.

Keywords: Diaphragmatic hernia; Intestinal obstruction
\end{abstract}

\section{Introduction}

Congenital diaphragmatic hernia $(\mathrm{CDH})$ occurs in 1 per 2 to 5 thousand live births. Most cases of CDH present immediately after birth with respiratory symptoms. Only $10-20 \%$ patients present later with recurrent respiratory illness [1]. $\mathrm{CDH}$ presenting as intestinal obstruction in an older child is very rare [2,3]. We treated two patients of $\mathrm{CDH}$ presented with intestinal obstruction.

\section{Case Report}

\section{Case 1}

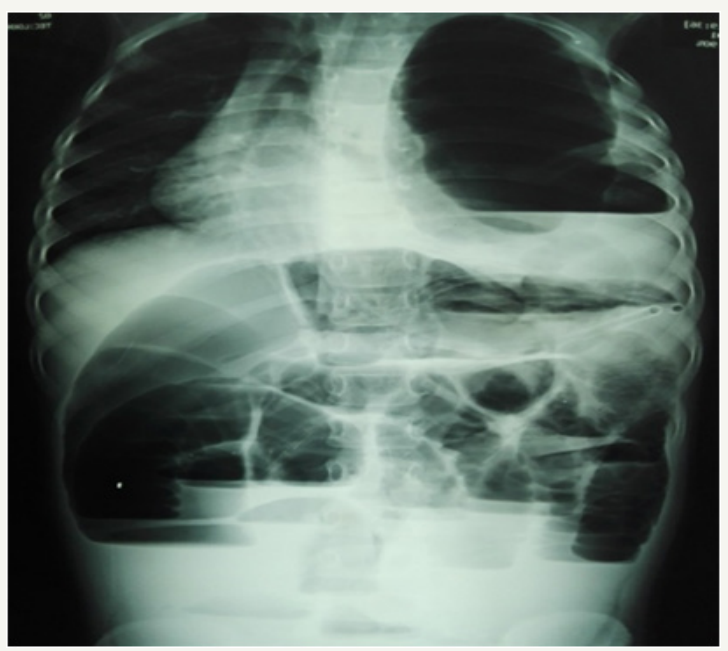

Figure 1: X-ray abdomen with chest (case1).

A 6 year old previously asymptomatic girl presented with 2 days history of abdominal distention, bilious vomiting and constipation. General examination revealed mild dehydration and tachycardia.

Abdomen was distended \& tender with loud bowel sound. Rectum was empty. Provisional diagnosis was intestinal obstruction due to congenital bands. $\mathrm{X}$ ray abdomen in erect posture including chest revealed distended bowel loops with multiple air fluid level, bowel loops in left hemi thorax and heart pushed to right (Figure 1). Other hematological and biochemical parameters were normal.

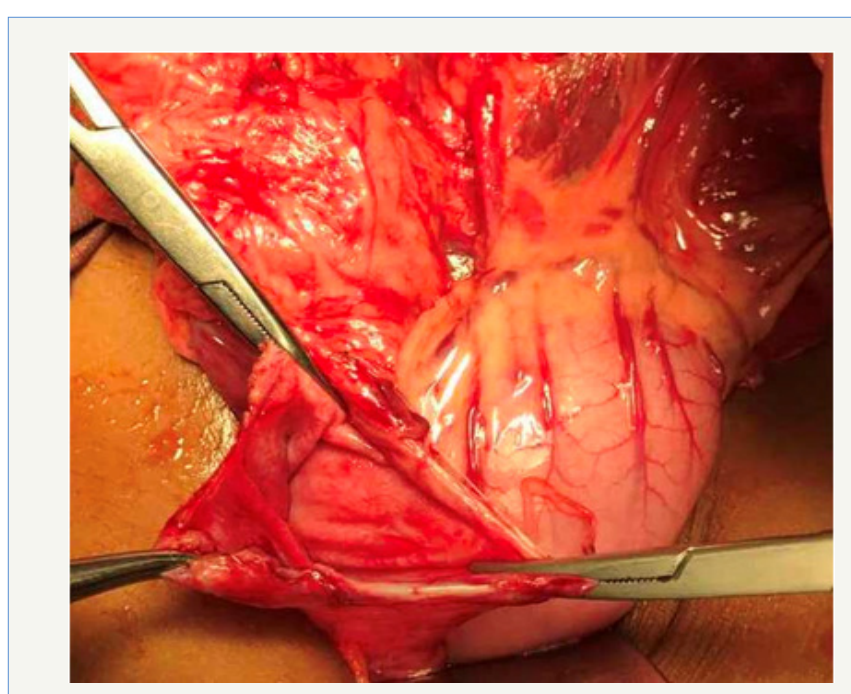

Figure 2: Opening in the diaphragm after release of obstruction (case 1).

Emergency laparotomy was performed. There was a small gap in the left hemi diaphragm through which a loop of sigmoid colon was obstructed in the chest cavity. The neck of the hernia was incised to relieve the obstruction (Figure 2). There was an area of ischemic necrosis on the ant mesenteric border of obstructed sigmoid colon, which was repaired. Diaphragmatic hernia was repaired with nonabsorbable suture. Post operative $\mathrm{x}$ ray was grossly normal. The patient recovered well. 


\section{Case 2}

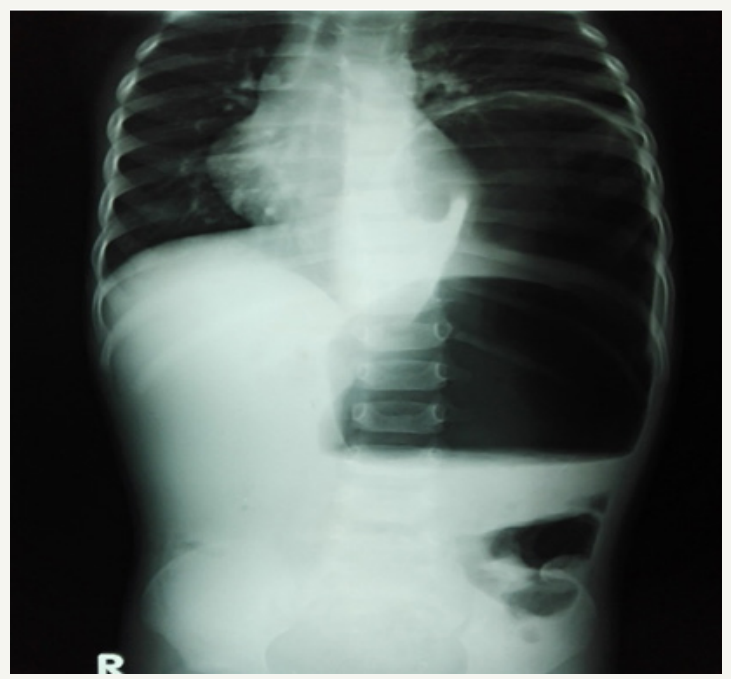

Figure 3: X-ray abdomen \& chest (case 2).

A two year old boy presented with abdominal distension, vomiting \& constipation. He had history of laparotomy and manual release of Intussusceptions at the age of 7 month. Physical examination revealed mild dehydration and tachycardia. Abdomen was distended, Bowel sound was present, rectum was empty. Provisional diagnosis was intestinal obstruction due to post operative band adhesion. $\mathrm{X}$ ray revealed intestinal obstruction with left sided diaphragmatic hernia (Figure 3). Abdomen was opened through left sub costal incision, diaphragmatic hernia with sac found (Figure 4). After reposition of gut hernia was repaired with non absorbable suture. Post operative period was uneventful.

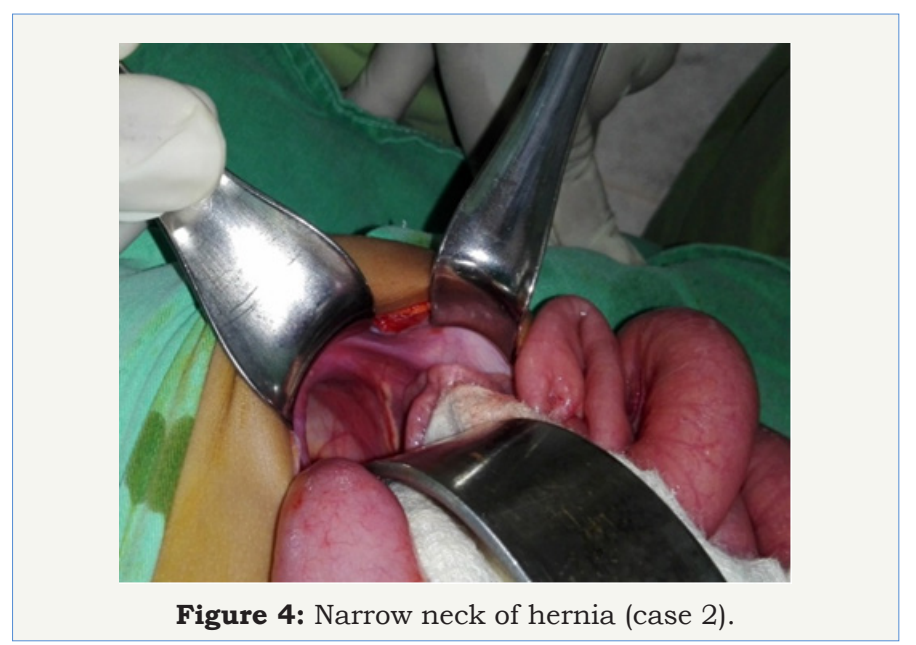

\section{Discussion}

Causes of delayed presentation of $\mathrm{CDH}$ are either late rupture of small hernial sac or plugging of the hernial defect by solid viscera
$[2,4]$. Only few authors reported intestinal symptoms in patients with diaphragmatic hernia. During our initial examination, we missed the respiratory findings of these patients as there were no respiratory complaints and this condition is not so common. Rawat et al. [5] have reported two children with $\mathrm{CDH}$ and intestinal obstruction, one in left side and another in right side. Koh et al. [6] reported a case of obstructed diaphragmatic hernia with transverse colon perforation. In our 1st case we found ischemic necrosis \& perforation at sigmoid colon but gut was healthy in second case. In both cases narrow neck of the hernia was responsible for obstruction.

Horton et al. [3] reported two cases of obstructed hernia where stomach was the content. Burki et al. [7] also reported delayed presentation of Bochdalek hernia with intestinal symptoms. Alimoglu et al. [8] and Christianser et al. [9] reported strangulated diaphragmatic hernia following traumatic rupture of diaphragm. Both of our patients recovered well because pulmonary hypoplasia and hypertension are not prominent in older children with diaphragmatic hernia but delay in diagnosis may cause strangulation of intestine. Obstructed diaphragmatic hernia is a rare cause of intestinal obstruction in children. High index of suspicion is required for diagnosis and early diagnosis and management avoid intestinal complications. $\mathrm{X}$ ray is the primary and most important diagnostic tool.

\section{References}

1. Stolar CJH, Dillon PW (2012) congenital diaphragmatic hernia and event ration. In: Coran AG, et al. (Eds), Pediatric Surgery. ( $7^{\text {th }}$ edn), Elsevier, Philadelphia, pp: 809-824.

2. Tauro LF, Rao SS, Hegde BR, Peter AI, Gulvadi RK (2006) Obstructed/ strangulated diaphragmatic hernia: A rare cause of acute intestinal obstruction in adults. Ind J Thorac Cardiovasc Surg 22: 233-235.

3. Horton J, Hammond JDS (1960) Incarcerated and obstructed diaphragmatic hernia. Thorax 15: 59-63.

4. Singh TC, Singh CG, Lamare KN, Babitha N, Kharnaior A (2015) Congenital Diaphragmatic Hernia in Adult Presenting with Obstruction: A Rare Case. International Journal of Scientific Study, 2(10): 142-145.

5. Rawat JD, Kureel SN, Tendon RK, Tendon S, Wakhar AK (1999) Obstructed diaphragmatic hernia. J Indian Assoc Paed Surgeons 4: 34-38.

6. Koh H, Sivarajah S, Anderson D, Wilson C (2012) Incarcerated diaphragmatic hernia as a cause of acute abdomen. J Surg Case Rep 2012(10): 4.

7. Burki T, Amanullah A, Rehman AU, Ali MN (2002) Late presentation of Bochdalek hernia with intestinal symptoms, J Ayub Med Coll Abbottabad 14(3): 27-28.

8. Alimoglu O, Eryilmaz R, Sahin M, Ozsoy MS (2004) Delayed traumatic diaphragmatic hernias presenting with strangulation. Hernia 8(4): 393396.

9. Christiansen LA, Blichert-Toft M, Bertelsan S (1975) Strangulated diaphragmatic hernia, a clinical study. Am J Surg 129: 574-578. 
For possible submission use the below is the URL

Your subsequent submission with Crimson Publishers will attain the below benefits

- High-level peer review and editorial services

- Freely accessible online immediately upon publication

- Authors retain the copyright to their work

- Licensing it under a Creative Commons license

- Visibility through different online platforms

- Global attainment for your research

- Article availability in different formats (Pdf, E-pub, Full Text)

- Endless customer service

- Reasonable Membership services

- Reprints availability upon request

- One step article tracking system 